\title{
MODEL EPIDEMIK SEIR PADA KASUS PENYAKIT JANTUNG KORONER PADA PENDERITA KOLESTROL
}

\author{
A.F. Akadji ${ }^{1 *}$, K.A. Mamonto ${ }^{2}$, A.F.D. Hubu ${ }^{3}$, M.S. Ismail ${ }^{4}$ \\ 1,2,3,4 Jurusan Matematika, Universitas Negeri Gorontalo, Bone Bolango 96119, Indonesia \\ *Penulis Korespondensi. Email: farhanah.akadji@gmail.com
}

\begin{abstract}
Abstrak
Penyakit janting koroner (PJK) disebabkan oleh berbagai macam sebab. Salah satu penyebab utama penyakit jantung koroner adalah kolestrol. Kolestrol datang dari dua sumber yaitu, yang diproduksi oleh hati dan melalui makanan yang dikonsumsi. Dalam artikel ini dibahas model atematika penyakit jantung koroner yang mengacu pada model SEI (Susceptible-exposed-infected), dengan modifikasi berupa penambahan variabel recovered $(R)$ dan parameter berupa pola hidup sehat dan operasi. Selanjutnya model ini disebut model SEIR (Susceptible-Exposed-Infected-Recovered). Penelitian ini bertujuan untuk memokdelkan masalah penyakit jantung koroner pada penderita kolestrol dan menganalisis pengaruh parameter operasi dan pola hidup sehat terhadap penyembuhan penderita, Berdasarkan hasil penelitian yang diperoleh, seakin tinggi laju perubahan karena pola hidup sehat dan penambahan parameter operasi mengakibatkan nila peluang inividu recovered $(R)$ lebih tinggi dibandingkan dengan nilai peluang pada kelopok yang lain. Dan nilai peluang individu infected jauh lebih rendah dibandingkan dengan kelompok lain. Hal ini menunjukan bahwa peluang sembuh bagi penderita penyakit jantung koroner dengan jalur operasi tinggi.
\end{abstract}

Kata Kunci: Model SEIR; Jantung Koroner; Kolestrol

\begin{abstract}
Coronary heart disease (CHD) is caused by various reasons. One of the main causes of coronary heart disease is cholesterol. Cholesterol comes from two sources, namely, that which is produced by the liver and through the food consumed. This article discusses the mathematical model of coronary heart disease which refers to the SEI (Susceptible-exposed-infected) model, with modifications in the form of the addition of the recovered $(R)$ variable and parameters in the form of a healthy lifestyle and surgery. Hereinafter this model is called the SEIR (Susceptible-ExposedInfected-Recovered) model. This study aims to determine the problem of coronary heart disease in cholesterol sufferers and to analyze the effect of operating parameters and a healthy lifestyle on the patient's healing $(R)$ is higher than the opportunity value of the other groups. And the opportunity value of an infected individual is much lower than that of other groups. This shows that the chances of recovery for people with coronary heart disease with a high operating route.
\end{abstract}

Keywords: SEIR Model; Coronary Heart; Cholesterol

\section{Pendahuluan}

Pemodelan matematika merupakan salah satu teknik dalam matematika yang mempresentasikan fenomena-fenomena nyata ke dalam bentuk matematika. Model matematika banyak diaplikasikan dalam berbagai bidang ilmu, salah satunya bidang kesehatan. Kesehatan merupakan hal yang sangat penting namun banyak orang yang tidak mempedulikan hal tersebut. Efek yang ditimbul dari ketidakpedulian ini sangat beragam, salah satunya dapat menimbulkan penyakit mematikan seperti jantung koroner [1][2].

Data World Health Organization (WHO) tahun 2012 menunjukkan 17,5 juta orang di dunia meninggal akibat penyakit kardiovaskuler atau 31\% dari 56,5 juta kematian di seluruh dunia. Lebih 
dari $3 / 4$ kematian akibat penyakit kardiovaskuler terjadi di negara berkembang yang berpenghasilan rendah sampai sedang. Dari seluruh kematian akibat penyakit kardiovaskuler 7,4 juta (42,3\%) diantaranya disebabkan oleh oleh Penyakit Jantung Koroner (PJK) dan 6,7 juta $(38,3 \%)$ disebabkan oleh stroke [3].

Persoalan akan timbul bila oleh sesuatu sebab terdapat halangan atau kelainan di arteri koroner, sehingga tidak cukup suplai darah, yang berarti juga kurangnya suplai oksigen dan nutrisi untuk menggerakkan jantung secara normal. Keadaan diatas dikenal sebagai penyakit jantung koroner (PJK) [4].

Salah satu faktor tertinggi yang menyebabkan penyakit jantung koroner adalah kolesterol. Kolesterol merupakan senyawa dengan sifat mirip lemak yang hidup secara alami dalam hampir setiap bagian tubuh seperti otak, saraf, oto, usus, hati, dan jantung. Kolesterol datang dari dua sumber yaitu, yang diproduksi oleh hati dan melalui makanan yang dikonsumsi.

Kolesterol terbagi atas dua yaitu kolesterol baik atau High Density Lipoprotein (HDL) dan kolesterol jahat atau Low Density Lipoprotein (LDL). HDL bertugas untuk menghalau dan mencegah penimbunan kolesterol jahat dalam arteri dengan mengangkut kolesterol dari jaringan tubuh ke hati untuk dibuang. Sedangkan LDL bertugas membawa kolesterol ke jaringan tubuh atau ke hati untuk diedarkan kembali. LDL berjumlah 60\% - 70\% dari total kadar kolesterol dalam tubuh sehingga LDL bisa menumpuk dalam arteri dan menyebabkan berbagai macam penyakit termasuk penyaakit jantung koroner [5].

Sebelumnya masalah penyakit jantung koroner telah dibahas dalam [1] dengan menggunakan model SEI dengan populasi yang mempertimbangkan 4 faktor yaitu kolesterol, diabetes melitus, hipertensi, dan perokok. Namun pada penelitian ini kami menggunakan model SEIR dengan menambahkan parameter operasi dan pola hidup sehat dimana populasi yang digunakan hanya penderita kolesterol. Dengan memodelkan populasi penderita kolesterol dengan parameter operasi dan pola hidup sehat kedalam bentuk model matematika dan merumuskan strategi untuk mengendalikan laju peningkatan jumlah penyakit jantung koroner, maka diharapkan dapat membantu untuk memprediksi jumlah penderita penyakit jantung koroner. Penelitian ini dilakukan dengan tujuan untuk menerapkan model SEIR pada penyakit jantung koroner dan menganalisis pengaruh parameter operasi dan pola hidup sehat terhadap penyembuhan penderita.

\section{Metode Penelitian}

Penelitian ini menggunakan metode penelitian studi literatur (library research). Pada penelitian ini dilakukan kajian terhadap buku, textbook, jurnal, dan artikel-artikel ilmiah mengenai penyakit jantung koroner pada penderita kolesterol dan mengkaji model SEIR.

Pada penelitian ini, adapun langkah-langkah yang dilakukan adalah

1) Memodelkan dan memodifikasi masalah kedalam model SEIR,

2) Menentukan titik tetap,

3) Menentukan matriks jacobi,

4) Menganalisis kestabilan titik tetap, dan

5) Simulasi. Pembahasan

\section{Hasil dan Pembahasan}

\subsection{Model Matematika}

Model yang akan dibahas adalah model SEIR penyakit jantung koroner pada penderita kolesterol. Terdapat 4 populasi pada model ini, yaitu: Susceptible (populasi rentan), Exposed (populasi terpapar/ bergejala PJK), Infected (populasi sakit), dan Recovered (populasi sembuh). Adapun parameterparameter yang digunakan, disajikan pada Tabel 1, dengan asumsi-asumsi yang digunakan, antara lain: 
1. Jumlah kelahiran selalu konstan.

2. Kelompok Susceptible merupakan populasi yang menderita Kolesterol. Kelompok Exposed merupakan populasi terpapar atau sudah memiliki gejala PJK. Kelompok Infected merupakan populasi positif PJK. Dan kelompok Recovered merupakan populasi yang sembuh dari PJK dan terhindar dari kolesterol LDL tinggi selama menjaga pola hidup sehat.

3. Ada individu didalam kelompok Susceptible dan Exposed yang memiliki pola hidup yang buruk.

4. Laju kematian alami setiap populasi beda.

5. Ada Individu pada kelompok Infected merubah pola hidup.

6. Ada individu yang sembuh total.

7. Faktor genetik diabaikan.

Tabel 1. Keterangan parameter

\begin{tabular}{lc}
\hline \multicolumn{1}{c}{ Pernyataan } & Simbol \\
\hline Penambahan individu secara konstan pertahun & $\xi$ \\
Laju perubahan kelompok susceptible ke & $\mathrm{A}$ \\
exposed karena pola hidup tidak sehat & $\delta_{1}$ \\
Kematian alami untuk kelompok susceptible & $\delta_{2}$ \\
Kematian alami untuk kelompok exposed & $\delta_{3}$ \\
Kematian alami untuk kelompok infected & $\delta_{4}$ \\
Kematian alami untuk kelompok recovered & $\theta_{1}$ \\
Laju perubahan kelompok exposed ke infected & $\theta_{2}$ \\
Laju perubahan kelompok infected ke exposed & $\phi$ \\
Kematian akibat penyakit jantung koroner & $\mathrm{B}$ \\
Laju perubahan kelompok infected ke recovered & \\
melalui operasi & \\
\hline
\end{tabular}

Secara sekamatis, kasus ini dapat digambarkan dalam bentuk diagram kompartmen pada Gambar 1.

1- $\alpha$

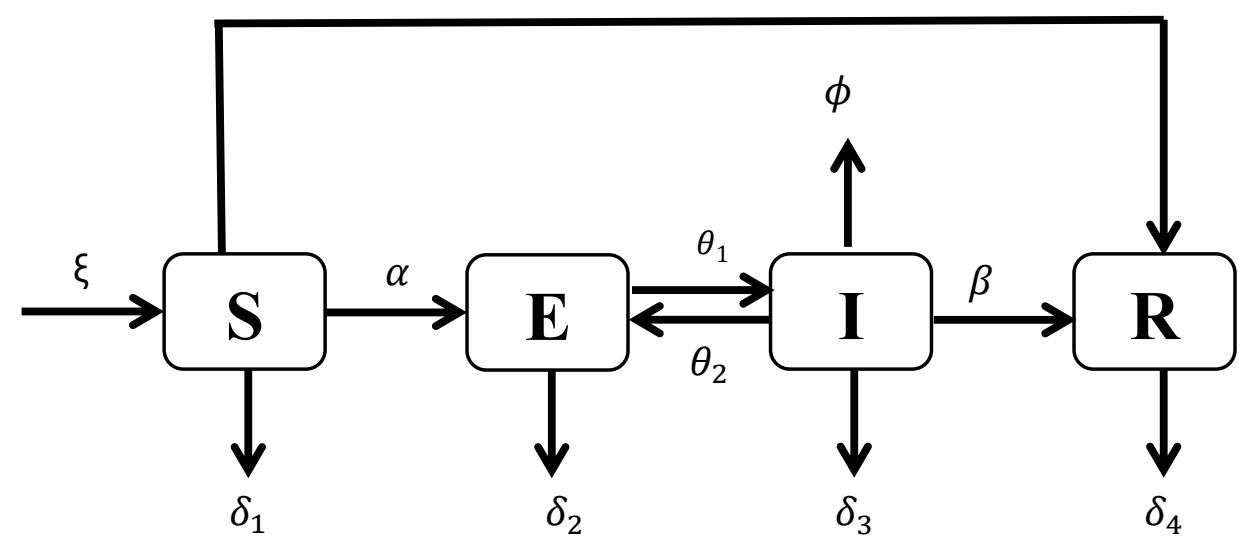

Gambar 1. Diagram kompartemen model SEIR

Berdasarkan Gambar 1, diperoleh model dari permasalahan ini, yaitu: 


$$
\begin{aligned}
& \frac{d S}{d t}=\xi-\left(\delta_{1}+\alpha+(1-\alpha)\right) S \\
& \frac{d E}{d t}=\alpha \mathrm{S}+\theta_{2} I-\left(\theta_{1}+\delta_{2}\right) E \\
& \frac{d I}{d t}=\theta_{1} \mathrm{E}-\left(\delta_{3}+\beta+\theta_{2}+\phi\right) I \\
& \frac{d R}{d t}=\beta \mathrm{I}+(1-\alpha) S-\delta_{4} R
\end{aligned}
$$

\subsection{Penentuan Titik Tetap}

Titik tetap model matematika dinamika populasi penderita penyakit jantung koroner bagi peng idap kolesterol diperoleh dengan menetapkan persamaan-persamaan pada sistem persamaan menjadi konstan terhadap waktu atau $\frac{d s}{d t}=0, \frac{d e}{d t}=0, \frac{d i}{d t}=0$, dan $\frac{d r}{d t}=0$ sehingga sistem persamaan dapat ditulis sebagai berikut:

$$
\left\{\begin{array}{l}
\xi-\left(\delta_{1}+1\right) s=0 \\
\alpha s-\left(\delta_{2}+\theta_{1}\right) e+\theta_{2} i=0 \\
\theta_{1} e-\left(\delta_{3}+\beta+\theta_{2}+\phi\right) i=0 \\
\beta i-\delta_{4} r+(1-\alpha) s=0
\end{array}\right.
$$

Dari hasil analisis dan bantuan software Maple pada persamaan (5) di dapat satu jenis titik tetap yaitu titik tetap endemik. Titik tetap endemik untuk penyakit jantung koroner dapat dinyatakan dalam bentuk $\mathrm{E}_{1}=(\mathrm{s}, \mathrm{e}, \mathrm{i}, \mathrm{r})$, dimana

$$
\begin{aligned}
s & =\frac{\xi}{\delta_{1}+1} \\
e & =\frac{\left(\delta_{3}+\beta+\theta_{2}+\phi\right) \alpha \xi}{\left(\delta_{1}+1\right)\left(\beta \delta_{2}+\beta \theta_{1}+\delta_{2} \delta_{3}+\theta_{1} \delta_{3}+\phi \delta_{2}+\theta_{2} \delta_{2}+\theta_{1} \phi\right)} \\
i & =\frac{\alpha \xi \theta_{1}}{\left(\delta_{1}+1\right)\left(\beta \delta_{2}+\beta \theta_{1}+\delta_{2} \delta_{3}+\theta_{1} \delta_{3}+\phi \delta_{2}+\theta_{2} \delta_{2}+\theta_{1} \phi\right)} \\
r & =\frac{-\left(\xi\left(\alpha \beta \delta_{2}+\alpha \delta_{2} \delta_{3}+\alpha \theta_{1} \delta_{3}+\alpha \phi \delta_{2}+\alpha \theta_{2} \delta_{2}+\alpha \theta_{1} \phi-\beta \delta_{2}-\beta \theta_{1}-\delta_{2} \delta_{3}-\theta_{1} \delta_{3}-\phi \delta_{2}-\theta_{2} \delta_{2}-\theta_{1} \phi\right)\right)}{\left(\beta \delta_{2}+\beta \theta_{1}+\delta_{2} \delta_{3}+\theta_{1} \delta_{3}+\phi \delta_{2}+\theta_{2} \delta_{2}+\theta_{1} \phi\right) \delta_{4}\left(\delta_{1}+1\right)}
\end{aligned}
$$

\subsection{Analisis Kestabilan Titik Tetap}

Model matematika penyakit jantung koroner untuk pengidap penyakit kolesterol merupakan sistem persamaan diferensial linear. Untuk menganalisis kestabilan titik tetap suatu persamaan diferensial linear, tidak diperlukan pelinearan persamaan diferensialnya[6][7][8]. Analisis kestabilan titik tetap dapat ditentukan dengan cara menentukan nilai eigen dari matriks Jacobian sistem. Untuk memperoleh kestabilan sistem di titik $E_{1}$ sehingga diperoleh matriks Jacobian dengan program Maple sebagai berikut:

$$
E_{1}=\left(\begin{array}{cccc}
-\delta_{1}-1 & 0 & 0 & 0 \\
\alpha & -\theta_{1}-\delta_{2} & 0 & 0 \\
0 & \theta_{1} & -\beta-\delta_{3}-\phi-\theta_{2} & 0 \\
1-\alpha & 0 & \beta & -\delta_{4}
\end{array}\right)
$$

Suatu titik tetap dikatakan stabil jika semua nilai eigen dari matriks jacobiannya bernilai negatif. Untuk mencari nilai eigen dapat dilakukan dengan menyelesaikan persamaan (6) menggunakan persamaan karakteristik, 


$$
\operatorname{det}(\lambda I-\beta)=0
$$

sehingga diperoleh nilai-nilai eigen, yaitu:

$$
\begin{aligned}
& \lambda_{1}=-\delta_{1}-1 \\
& \lambda_{2}=-\theta_{1}-\delta_{2} \\
& \lambda_{3}=-\beta-\delta_{3}-\phi-\theta_{2} \\
& \lambda_{4}=-\delta_{4}
\end{aligned}
$$

Karena $\lambda_{1}<0, \lambda_{2}<0, \lambda_{3}<0$, dan $\lambda_{4}<0$, maka dikatakan sistem ini stabil.

\subsection{Simulasi}

Selanjutnya akan dilakukan simulasi nilai-nilai parameter yang terdapat di dalam model dengan populasi awal $\mathrm{s}(0)=100$, e $(0)=70, \mathrm{i}(0)=21, \mathrm{r}(0)=10$. Adapun nilai parameter yang akan digunakan pada simulasi pertama dapat dilihat pada Tabel 2.

Tabel 2. Nilai parameter simulasi pertama

\begin{tabular}{lcc}
\hline \multicolumn{1}{c}{ Parameter } & Notasi & Nilai \\
\hline Penambahan individu secara konstan pertahun & $\xi$ & 100 \\
Laju perubahan kelompok susceptible ke exposed karena pola hidup & $\alpha$ & 0,7 \\
tidak sehat & $\delta_{1}$ & 0,05 \\
Kematian alami untuk kelompok susceptible & $\delta_{2}$ & 0,04 \\
Kematian alami untuk kelompok exposed & $\delta_{3}$ & 0,02 \\
Kematian alami untuk kelompok infected & $\delta_{4}$ & 0,03 \\
Kematian alami untuk kelompok recovered & $\theta_{1}$ & 0,3 \\
Laju perubahan kelompok exposed ke infected & $\theta_{2}$ & 0,1 \\
Laju perubahan kelompok infected ke exposed & $\Phi$ & 0,04 \\
Kematian akibat penyakit jantung koroner & $\beta$ & 0,5 \\
Laju perubahan kelompok infected ke recovered melalui operasi & & \\
\hline
\end{tabular}

Dengan menggunakan nilai parameter pada Tabel 2, diperoleh dinamika yang dapat dilihat pada Gambar 2.

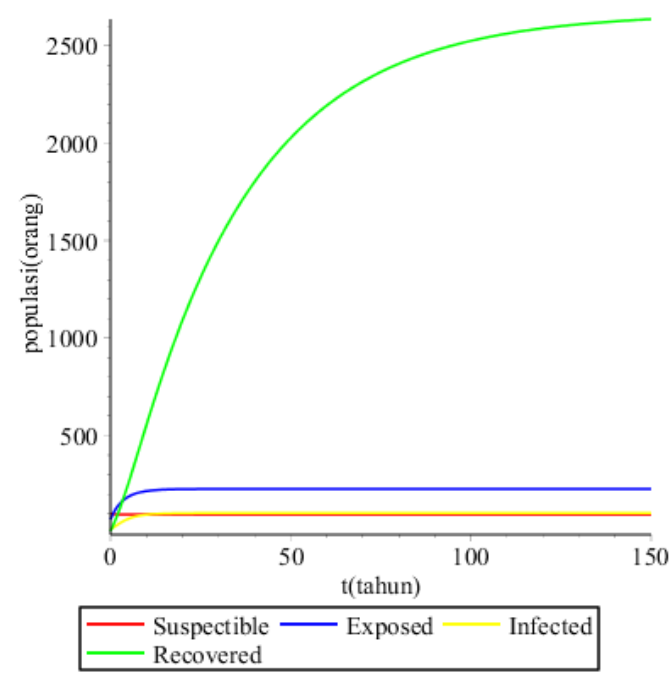

Gambar 2. Plot simulasi pertama

Dari Gambar 2, dapat dilihat bahwa pada sepuluh tahun pertama jumlah populasi kelompok S menurun sedangkan jumlah populasi kelompok E dan I terus mengalami peningkatan. Dan dapat dilihat, setelah sepuluh tahun jumlah populasi kelompok I lebih banyak dibanding kelompok S. 
Selain itu, peningkatan jumlah populasi kelompok E dan I menyebabkan peningkatan drastis pada kelompok R. Dan dapat dilihat, setelah $\mathrm{t}=100$, grafik konstan menuju titik ekuilibrium endemik pada $E_{1}=(\mathrm{s}, \mathrm{e}, \mathrm{i}, \mathrm{r})=(95.238,226.34,102.88,2667.06)$. Pada simulasi kedua, dignakan nilai-nilai parameter pada Tabel 3.

Tabel 3. Nilai parameter simulasi kedua

\begin{tabular}{lcc}
\hline \multicolumn{1}{c}{ Parameter } & Notasi & Nilai \\
\hline Penambahan individu secara konstan pertahun & $\xi$ & 100 \\
$\begin{array}{l}\text { Laju perubahan kelompok susceptible ke exposed karena pola } \\
\text { hidup tidak sehat }\end{array}$ & $\alpha$ & 0,5 \\
\hline Kematian alami untuk kelompok susceptible & $\delta_{1}$ & 0,05 \\
Kematian alami untuk kelompok exposed & $\delta_{2}$ & 0,04 \\
Kematian alami untuk kelompok infected & $\delta_{3}$ & 0,02 \\
Kematian alami untuk kelompok recovered & $\delta_{4}$ & 0,03 \\
Laju perubahan kelompok exposed ke infected & $\theta_{1}$ & 0,3 \\
Laju perubahan kelompok infected ke exposed & $\theta_{2}$ & 0,5 \\
Kematian akibat penyakit jantung koroner & $\Phi$ & 0,031 \\
Laju perubahan kelompok infected ke recovered melalui & $\beta$ & 0,5 \\
operasi & $\beta$ & \\
\hline
\end{tabular}

Dengan menggunakan nilai-nilai parameter pada Tabel 3, diperoleh Gambar 3.

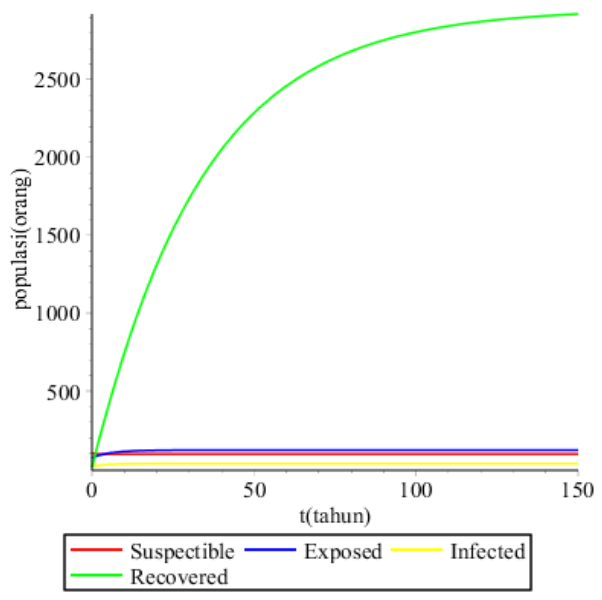

Gambar 3. Plot simulasi kedua

Dari grafik pada Gambar 3. jumlah populasi kelompok S mengalami sedikit penurunan. Dan kelompok E dan I mengalami peningkatan. Pada tiga tahun pertama, jumlah populasi kelompok E lebih banyak dari kelompok S, namun jumlah populasi kelompok I tidak lebih banyak dari kelompok E dan S. Selain itu, peningkatan jumlah populasi kelompok E dan I menyebabkan peningkatan juga pada kelompok R. Dan dapat dilihat, setelah $\mathrm{t}=100$, grafik konstan menuju titik ekuilibrium endemik $E_{1}=(\mathrm{s}, \mathrm{e}, \mathrm{i}, \mathrm{r})=(95.238,120.69,34.45,2955.119)$.

Dan untuk simulasi ketiga, adapun nilai parameter yang akan digunakan dapat dilihat pada Tabel 4 dan diperoleh plot pada Gambar 4. Grafik pada Gambar 4. jumlah populasi kelompok S mengalami sedikit penurunan. Dan kelompok E dan I mengalami peningkatan. Pada lima belas tahun pertama, jumlah populasi kelompok $S$ sedikit lebih banyak daripada kelompok I. Selain itu, peningkatan jumlah populasi terjadi pada kelompok E dan R. Dapat dilihat, setelah $\mathrm{t}=50$, populasi $\mathrm{S}$ dan I hampir sama. Dan setelah $\mathrm{t}=100$, grafik konstan menuju titik ekuilibrium endemik $\mathrm{E}_{1}=(\mathrm{s}, \mathrm{e}, \mathrm{i}, \mathrm{r})=(95.238,414.348,92.764,2498.454)$. 


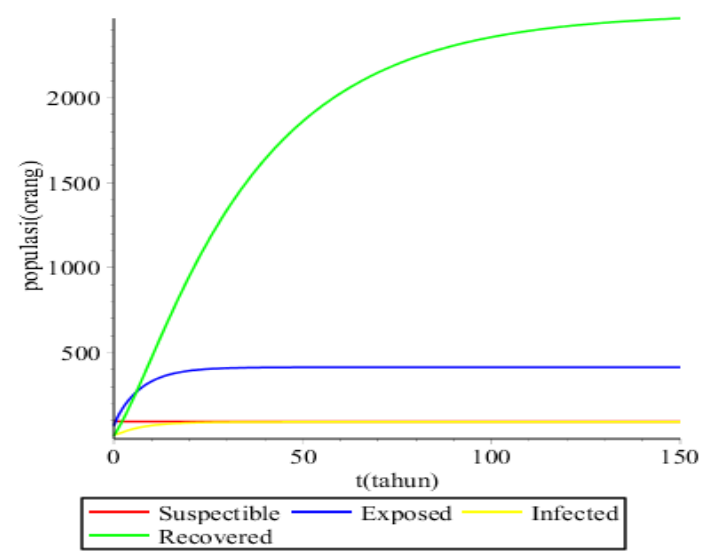

Gambar 4. Plot simulasi ketiga

Tabel 4. Nilai parameter simulasi ketiga

\begin{tabular}{lcc}
\hline \multicolumn{1}{c}{ Parameter } & Notasi & Nilai \\
\hline Penambahan individu secara konstan pertahun & $\xi$ & 100 \\
Laju perubahan kelompok susceptible ke exposed karena pola & $\mathrm{A}$ & 0,25 \\
hidup tidak sehat & $\delta_{1}$ & 0,05 \\
Kematian alami untuk kelompok susceptible & $\delta_{2}$ & 0,04 \\
Kematian alami untuk kelompok exposed & $\delta_{3}$ & 0,02 \\
Kematian alami untuk kelompok infected & $\delta_{4}$ & 0,03 \\
Kematian alami untuk kelompok recovered & $\theta_{1}$ & 0,30 \\
Laju perubahan kelompok exposed ke infected & $\theta_{2}$ & 0,80 \\
Laju perubahan kelompok infected ke exposed & $\Phi$ & 0,02 \\
Kematian akibat penyakit jantung koroner & $\beta$ & 0,50 \\
Laju perubahan kelompok infected ke recovered melalui operasi & & \\
\hline
\end{tabular}

Dari hasil pembahasan diatas, dapat disimpulkan bahwa untuk model SEIR penyakit jantung koroner bagi penderita kolesterol, jumlah populasi kelompok $S$ hanya akan mengalami sedikit penurunan, dan berbanding terbalik dengan jumlah populasi kelompok $\mathrm{R}$ yang terus meningkat. Perubahan selisih jumlah populasi antara kelompok S dan I terjadi apabila nilai parameter $\theta_{2}$ dan $\Phi$ mengalami perubahan. Pada simulasi pertama, nilai parameter $\theta_{2}=0.1$ dan $\Phi=0.04$ yang menghasilkan jumlah populasi kelompok I lebih besar daripada kelompok I pada simulasi kedua dan ketiga. Sedangkan pada simulasi ketiga, nilai parameter $\theta_{2}=0.8$ dan $\Phi=0.02$ yang menghasilkan jumlah populasi kelompok I lebih kecil daripada kelompok I pada simulasi pertama dan kedua. Perubahan pada nilai parameter $\alpha$ memberikan pengaruh pada jumlah populasi kelompok E, dan juga.perubahan yang signifikan pada kelompok I terjadi ketika nilai $\alpha$ diubah dari 0.7 menjadi 0.25. Dan parameter operasi $(\beta)$ yang merupakan satu-satunya jalur penyembuhan kelompok I menjadi R, memiliki peranan penting dalam peningkatan jumlah populasi kelompok R.

\section{Kesimpulan}

Untuk memperkecil jumlah populasi kelompok infected (I), disarankan kepada penderita kolesterol agar dapat menjaga pola hidup menjadi lebih sehat. Dan pengidap penyakit jantung koroner dapat melakukan penyembuhan dengan cara operasi agar populasi kelompok recovered (R) semakin meningkat. Dengan demikian dapat disimpulkan bahwa nilai parameter laju perubahan karena pola hidup tidak sehat $(\alpha)$ dan operasi $(\beta)$ sangat mempengaruhi jumlah populasi kelompok recovered $(R)$. 


\section{Referensi}

[1] W. Jannah and S. M. Yuni, "Pemodelan Penyakit Jantung Koroner Dengan Menggunakan Modifikasi Model SEI,” J. Konvergensi, vol. 51, pp. 1-7, 2015.

[2] W. Jannah, "Modifikasi Model Susceptible-Exposed-Infected (SEI) Untuk Pemodelan Penyakit Jantung Koroner," ETD Unsyiah, 2016. [Online]. Available: http://etd.unsyiah.ac.id/index.php?p=show_detail\&id=19798. [Accessed: 18-Sep-2018].

[3] Kemenkes, "Lingkungan Sehat, Jantung Sehat," Depkes, 2014. [Online]. Available: http://www.depkes.go.id/article/view/201410080002/lingkungan-sehat-jantung-sehat.html. [Accessed: 18-Sep-2018].

[4] I. Soeharto, Penyakit Jantung Koroner dan Serangan Jantung. Jakarta: Gramedia Pustaka Utama, 2004.

[5] K. Lorig, 50 Cara Menurunkan Kolesterol Anda. Jakarta: Prestasi Pustaka, 2004.

[6] H. Anton, Elementary Linear Algebra, 8th Edition. USA: Lehigh Press inc, 2000.

[7] S. Farlow, An Introduction To Differential Equation And Their Applications. New York: McGraw Hill, 1994.

[8] W. E. Boyce and R. C. Diprima, Elementery Differential Equation and Boundary Value Problems, 9th Edition. USA: John Wiley and Sons inc, 2009. 